\title{
Microcatheter Stabilization Technique Using Partially Inflated Balloon for Coil Embolization of Paraclinoid Aneurysms
}

\author{
Yunsun Song, $\mathrm{MD}, \mathrm{PhD}^{1}$, Boseong Kwon, $\mathrm{MD}^{1}$, Abdulrahman Hamad Al-abdulwahhab, $\mathrm{MD}^{2}$, \\ Ricky Gusanto Kurniawan, $\mathrm{MD}^{3}$, Dae Chul Suh, MD, PhD ${ }^{1}$ \\ ${ }^{1}$ Neurointervention Clinic, Department of Radiology, Asan Medical Center, University of Ulsan College of Medicine, Seoul, Korea \\ ${ }^{2}$ Diagnostic and Interventional Radiology Department, Imam Abdulrahman Bin Faisal University, King Fahd Hospital of the University, \\ Al-Khobar City, Saudi Arabia \\ ${ }^{3}$ Neurovascular Division National Brain Center Prof. Dr. Mahar Mardjono Hospital, Jakarta, Indonesia
}

\begin{abstract}
Purpose: Coil embolization of paraclinoid aneurysms should be simple, safe, and effective considering the benign nature of the aneurysm. Here, we present a microcatheter stabilization technique using a partially inflated balloon for the treatment of paraclinoid aneurysms.
\end{abstract}

Materials and Methods: This retrospective study included 58 patients who underwent balloon-assisted coiling (BAC) for unruptured paraclinoid aneurysms at a tertiary neuro-intervention center between January 2019 and March 2020. We applied a technique to stabilize the microcatheter's position using the modified BAC technique in paraclinoid aneurysms showing various projections around the ophthalmic curve of the internal carotid artery. The basic concept of the technique is to place a partially inflated balloon just distal to the aneurysm neck and support the distal curve of the microcatheter using the proximal bottom of the balloon. Immediate radiological outcomes were analyzed, and clinical outcomes were evaluated with modified Rankin Scale (mRS) scores.

Results: The BAC was successfully performed in 51 of 58 patients (88\%). We treated the remaining 7 patients by switching to stent-assisted coiling. We obtained a 37\% mean packing density resulting in favorable occlusion in all 58 aneurysms (complete occlusion in 35 and residual neck in 23). There were no intraprocedural thromboembolic or hemorrhagic events except one that revealed an asymptomatic infarction after the procedure (1.7\%). Magnetic resonance angiography follow-up was performed in 37 patients at an average of 11.8 months, in which 11 minor recurrences (29.7\%) were found. There was no major recurrence nor retreatment. The mRS score was 0 in all patients during a mean follow-up of 17.7 months (range, 12-25 months).

Conclusion: The modified balloon-assisted coiling technique using a partially inflated balloon was safe and effective and could serve as an option for treating paraclinoid aneurysms.

Key Words: Intracranial aneurysm; Embolization, therapeutic; Procedures and techniques utilization

\section{Correspondence to:} Dae Chul Suh, MD, PhD Neurointervention Clinic, Department of Radiology, Asan Medical Center, University of Ulsan College of Medicine, 88, Olympic-ro 43-gil, Songpa-gu, Seoul 05505, Korea Tel: +82-2-3010-4366

Fax: +82-2-3010-0090

E-mail:dcsuh@amc.seoul.kr

Received: April 3, 2021

Revised: May 10, 2021

Accepted: May 12, 2021
Copyright $\odot 2021$ Korean Society of Interventional Neuroradiology This is an Open Access article distributed under the terms of the Creative Commons Attribution Non-Commercial License (http://creativecommons.org/licenses/by-nc/4.0) which permits unrestricted non-commercial use, distribution, and reproduction in any medium, provided the original work is properly cited. 


\section{INTRODUCTION}

Paraclinoid aneurysms are generally defined as intracranial aneurysms that arise from an ophthalmic segment of the internal carotid artery (ICA) between the roof of the cavernous sinus and the origin of the posterior communicating artery. ${ }^{1,2}$ At present, an increasing number of patients with paraclinoid aneurysms are referred for endovascular treatment, which is performed using several different devices or techniques. ${ }^{3-6}$ Various microcatheter looping techniques and balloon-assisted and stent-assisted coiling have helped improve complete occlusion rates. ${ }^{1,7,8}$ However, because of the sharp curve from the carotid siphon and the large caliber of the paraclinoid ICA lumen, it is not always easy to maintain a stable microcatheter position while continuously inserting the coils into the aneurysm during the procedure. Besides, the aneurysmal dome of paraclinoid aneurysms is diversely directed into superior, posterior, medial, or lateral sides based on its relationship with the tight curve of the cavernous genu portion of the ICA. Shaping the microcatheter tip alone may not be sufficient to stabilize the microcatheter position according to the aneurysm location and relationship to the branching pattern at the aneurysm. ${ }^{9}$ Therefore, simple coiling of the paraclinoid aneurysm using only microcatheter shaping can result in incomplete packing or protrusion of the coils.

Balloon-assisted coil embolization has been used for aneurysms in various locations and has also been applied in paraclinoid aneurysms..$^{10-14}$ The conventional method of balloon inflation aims to protect the neck and prevent the coils from protruding out of the aneurysmal sac; to achieve such an effect, full inflation of the balloon is required. However, full inflation of the balloon at the neck of the aneurysm might have a mechanical conflict with the coil-delivering microcatheter in the aneurysm resulting in a displacement of the coil-delivering microcatheter to the ICA wall, especially in the tight curve of the cavernous genu. Such mechanical conflict may result in unexpected protrusion of coils, thereby leading to incomplete coiling of the aneurysm or even injury of the aneurysm wall, which may increase rupture risk. ${ }^{15-18}$ Therefore, we developed a modified balloon-assisted coiling technique with partial ballooning to improve outcomes by stabilizing microcatheter with improved coil packing. Here, we present the angiographic and clinical outcomes of 58 patients and discuss the technical concept.

\section{MATERIALS AND METHODS}

\section{Patients}

After Institutional Review Board approval, a retrospective review of patients treated with coil embolization at our institution was performed. Between January 2019 and March 2020, a total of 267 patients underwent endovascular treatment for unruptured, paraclinoid ICA aneurysms. Of these, 139 (52\%) received stent-assisted coiling, 58 were balloon-assisted (22\%), and 66 (25\%) were simply coiled. We included the 58 patients who underwent coil embolization using a balloon in this study. The participants consisted of 46 women and 12 men, with an average age of 53 years (range, 33-69 years). The treatment strategy was discussed by neurointerventionist and was based on each patient's risk factors. Flow diversion was not considered in this study because the government insurance does not cover a flow diverter for an aneurysm less than $15 \mathrm{~mm}$ in size in our country. ${ }^{19,20}$

\section{Aneurysm Characteristics}

Aneurysm location and projection were evaluated using a $3 \mathrm{D}$ rotational angiography from a biplane angiography system (Artis Zee; Siemens Healthcare, Forchheim, Germany). Paraclinoid aneurysms were defined as aneurysms arising at the ICA from the level of the ophthalmic artery to the supraclinoid ICA below the posterior communicating artery (Pco$\mathrm{mA}$ ) origin, which extends from the estimated distal border of the anterior genu of the cavernous carotid artery to the ostium of the PcomA. ${ }^{21}$ All the aneurysms were regarded as clearly or potentially intradural.

The aneurysms were categorized into four groups according to the origin and projection. Aneurysms in the superior group originated from the superior wall (dorsal wall) and projected superiorly or superomedially. Aneurysms in the medial group originated from the medial wall and projected medially or inferomedially. Aneurysms in the inferior group originated from the inferior wall (ventral or posterior wall) and projected inferiorly or posteroinferiorly. Aneurysms in the lateral group originated from the lateral wall and projected laterally or superolaterally. In our study, most of the aneurysms originating from the ophthalmic artery were categorized into the superior group (57.1\%), but in some cases, they were also categorized into the medial (28.6\%) or lateral (14.3\%) group depending on the location of the origin. We considered the categorization of aneurysm direction as critical because the vector of energy contained in a microcath- 
eter curve during coil introduction tended to be affected by the direction of the aneurysm from the ICA lumen.

According to the institutional protocol, the size, volume, and dome-to-neck ratio of the aneurysms were obtained from a routine measurement by radiological technologists. Wide-neck aneurysms were defined as those with a dometo-neck ratio of $<1.6 .{ }^{22}$ AngioCalc software (available at http://www.angiocalc.com) was used to calculate aneurysm volume and packing density after embolization.

\section{Procedure}

Forty-eight procedures (83\%) were performed with the patient under general anesthesia, while ten procedures (17\%) were initiated with conscious sedation and local anesthesia. All patients were pretreated with $100 \mathrm{mg}$ of aspirin and $75 \mathrm{mg}$ of clopidogrel daily for 5 days before the procedure. If the P2Y12 reaction units value indicated that the patient was resistant to clopidogrel, tailored medication with low-dose prasugrel was used instead. ${ }^{23-25}$ During the procedure, each patient received $70 \mathrm{IU} / \mathrm{kg}$ of intravenous heparin to attain an activated clotting time of approximately 250-300 seconds. Additional heparin at 1,000 IU per hour was administered to maintain the activated clotting time. After the microcatheter loop was advanced into the aneurysm, the aneurysm was packed as densely as possible with coils under the support of a balloon catheter (Fig. 1A-C). Patients who underwent balloon-assisted coiling received aspirin for one month after the procedure. We prescribed a 3-month course of dual anti- platelet agents, followed by an additional 3-month of aspirin monotherapy if a stent was used.

\section{Ballooning Strategies}

\section{Stabilization of the microcatheter loop via a partially inflated balloon}

We already described the loop microcatheter technique for paraclinoid aneurysms. ${ }^{26}$ However, the loop technique alone can sometimes be unstable while the coils are introduced into the aneurysm. In this situation, we additionally supported the microcatheter loop using a balloon catheter (Scepter $\mathrm{XC}^{\mathrm{TM}}$; Microvention, Tustin, CA, USA) with a double-lumen for guidewire and ballooning. Inflation was controlled to maintain the microcatheter loop shape while introducing the coils into the aneurysm (modified balloon-assisted coiling technique). We used a balloon with an oval shape rather than a tubular one to achieve such supportive effects. The basic concept was to keep the distal part of the loop abutting the lower bottom of the partially inflated balloon while the distal part of the loop (including the steam-shaped tip) was used for coiling (Figs. 1A-C, 2A-D)

\section{Stabilization of the 'pseudo-neck' of the paraclinoid aneurysm via a balloon catheter}

Even if the aneurysm seemed to have a neck, introduced coils were sometimes not securely contained within the aneurysm because of a weak neck, which allowed the wall
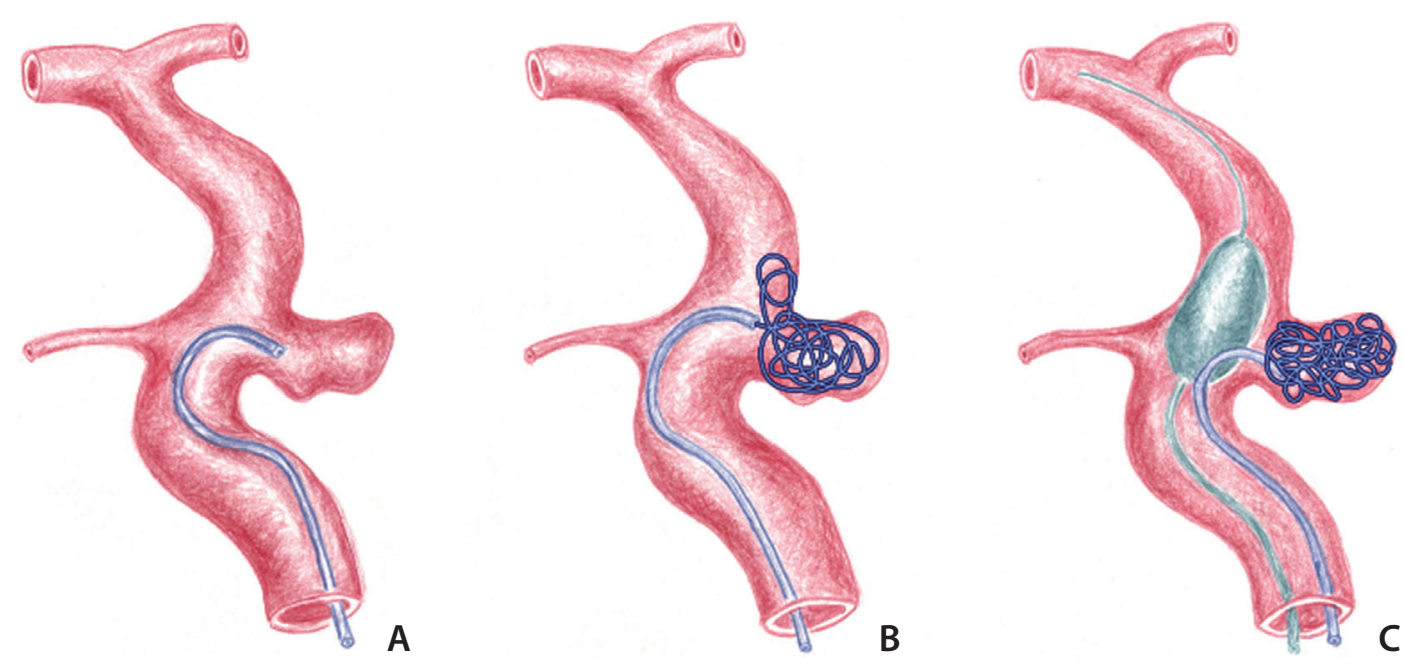

Fig. 1. Concept diagram depicting coiling of the paraclinoid aneurysm using a partially inflated balloon. (A) A loop-shaped microcatheter is introduced into the aneurysm. (B) The coil protrudes out of the aneurysm because of resistance of the coil within the aneurysm and withdrawal of the microcatheter. (C) Coil packing can be accomplished by supporting the microcatheter loop with the partially inflated balloon. 
forming the aneurysm neck to be easily opened by the protrusion of the frame coil (Fig. 3A-H); we call this a 'pseudo-neck' of the paraclinoid aneurysm. In this situation, the balloon was further inflated to support the wall of the neck without occluding the whole aneurysm neck.
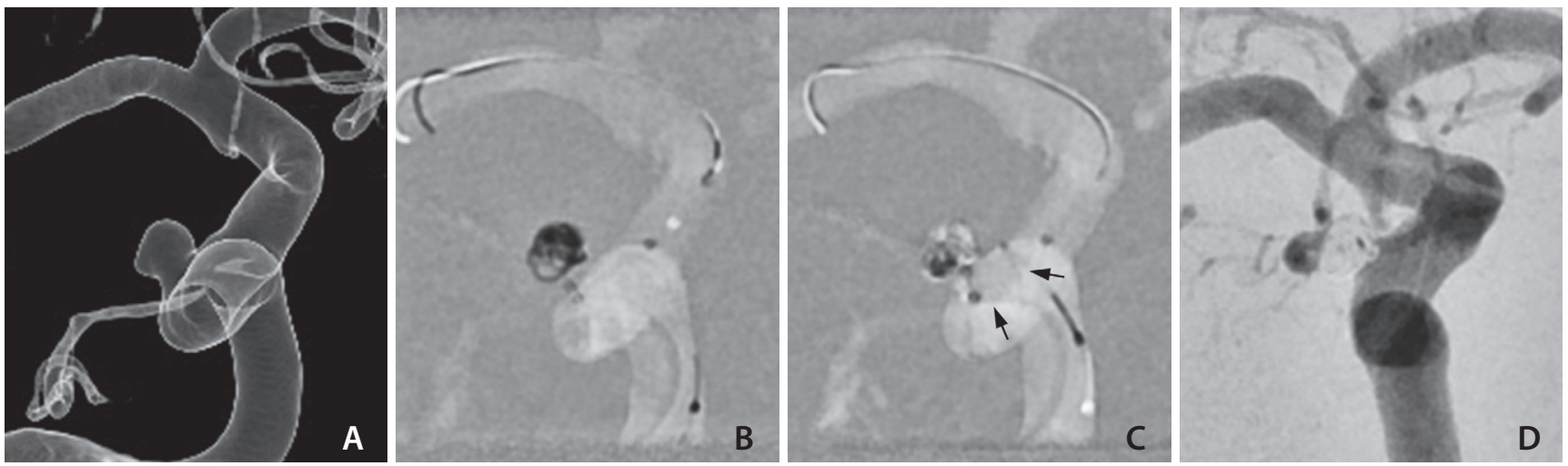

Fig. 2. Balloon-assisted coiling for the treatment of a paraclinoid aneurysm. (A) A 4-mm aneurysm with superolateral projection just distal to the anterior genus of the right cavernous internal carotid artery. (B, C) Framing and filling coils are inserted into the aneurysm by supporting the microcatheter with intermittent ballooning (arrows). (D) No contrast filling is seen in the aneurysm on completion angiogram. A tiny opacification within the coil mass was determined as an overlapping ophthalmic artery.
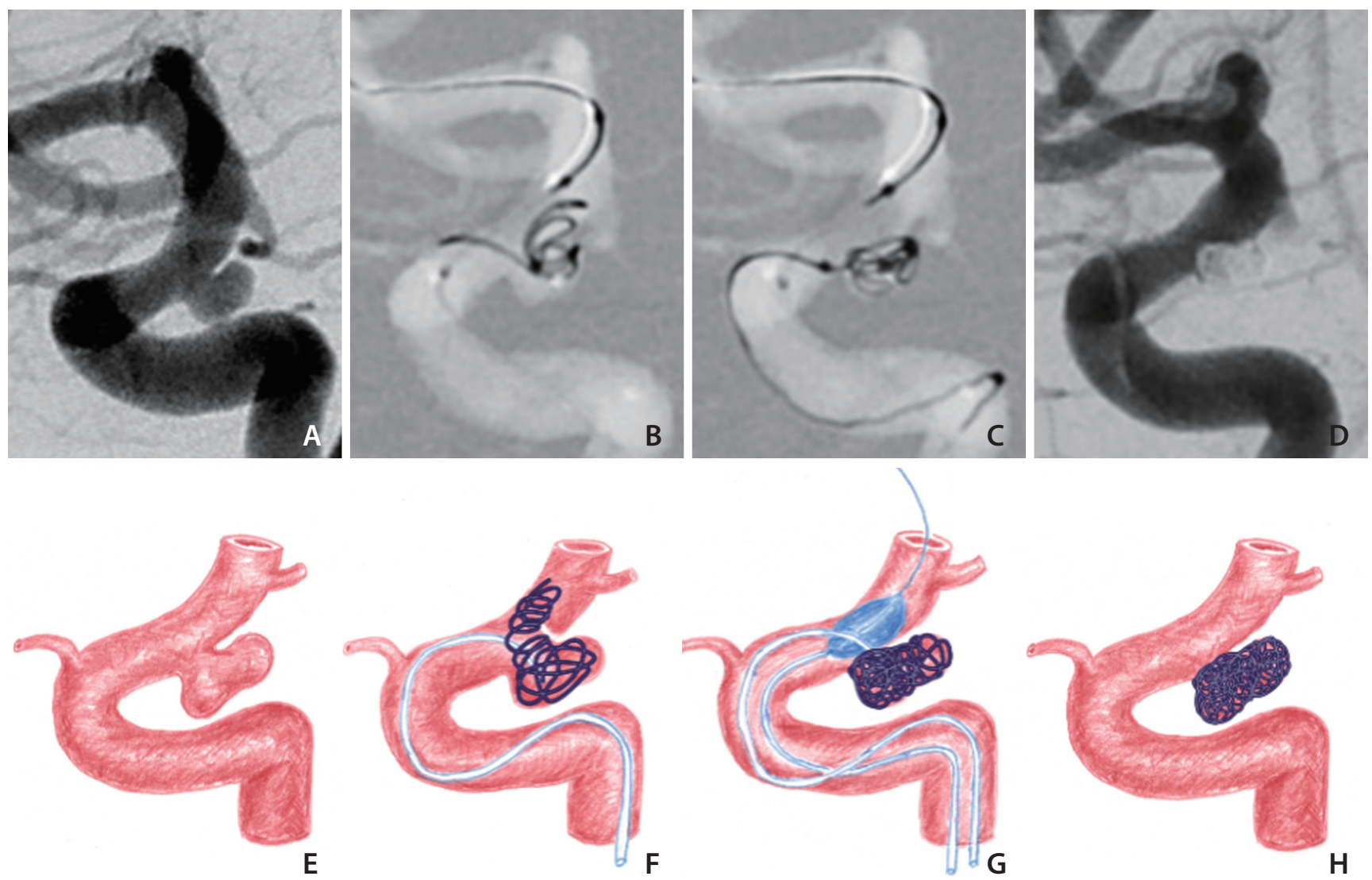

Fig. 3. A paraclinoid aneurysm with a relatively well-delineated neck as a pseudo-neck. (A) An internal carotid arteriogram shows an aneurysm at the posterior wall. (B) The aneurysm neck is not resistant to the coils and collapses while introducing the frame coil; thus it is regarded as a pseudo-neck. (C) The coils are contained within the aneurysm via the balloon inflation. (D) Final angiogram shows compact coiling of the aneurysm. (E-H) Concept diagrams of the procedure. 


\section{Stabilization of packed coils while retrieving the microcatheter at the end of coil embolization}

During retrieval of the microcatheter at the end of the coil embolization, the last inserted coil or some coil loops may protrude out of the aneurysm because of the hooking effect of the tightly looped microcatheter tip. This inadvertent effect can be prevented by point ballooning of the ovoid balloon catheter at the microcatheter tip. This point inflation allowed for safe retrieval of microcatheter and kept the degree and time of lumen occlusion minimal even if the full inflation was required.

\section{Conversion to stent-assisted coiling when balloon-assisted coiling is not available}

If the coiling was not secured by the balloon itself, we switched from a balloon- to stent-assisted coiling method $(n=7)$. For that purpose, we used a stent (NeuroForm Atlas ${ }^{\mathrm{TM}}$; Stryker Neurovascular, Fremont, CA, USA) that could be deployed via the same balloon catheter without any difficulty (Fig. 4A-D).

\section{Outcome Measures and Follow-up}

Technical success was defined as achieving stable microcatheter selection on an aneurysm and sufficient packing of coils without residual aneurysm using a balloon catheter. If a stent was used for any reason during balloon-assisted coiling, it was considered treatment failure regardless of the procedural outcome.

All patients underwent post-procedural magnetic resonance imaging within 24 hours, which included axial diffusion-weighted imaging (DWI) and time-of-flight (TOF) magnetic resonance angiography (MRA). All DWI high signal intensity lesions with decreased ADC (apparent diffusion coefficient) value located in the corresponding vascular territory were classified into acute thromboembolic infarction (larger than $5 \mathrm{~mm}$ in maximal diameters) and microembolism (mostly 1-2 mm in size, less than $5 \mathrm{~mm}$ ). ${ }^{27}$ The TOF-MRA was thoroughly reviewed using 3-dimensional rotational maximum intensity projection images and the source images. ${ }^{28}$

The procedural outcome was classified into complete obliteration, residual neck, and residual aneurysm, ${ }^{29}$ which was evaluated by considering the completion of digital subtraction angiography (DSA) and TOF-MRA. When the aneurysm was considered occluded despite minimal residual flow within the aneurysmal sac under systemic heparinization, a conclusion was reached considering the results of the MRA taken within 24 hours. Also, when it was difficult to evaluate residual aneurysms with DSA because of overlapping vessels or dense coils, TOF-MRA findings were considered for the decision.

The coil shape and position were routinely examined by simple skull radiography at each follow-up visit. An MRA follow-up was performed from 6 months to 2 years after the procedure according to the packing density and location of the aneurysms based on the operator's decision. A recurrence was defined as any increase in aneurysmal filling on the follow-up MRA. Major recurrence included an aneurysmal recurrence of more than $2 \mathrm{~mm}$, which provided an appropriate cavity for additional coils placement. ${ }^{30} \mathrm{~A}$ minor recurrence was defined as any recurrence that does not meet the criteria for major recurrence. Adverse events were defined as any complications during the periprocedural and
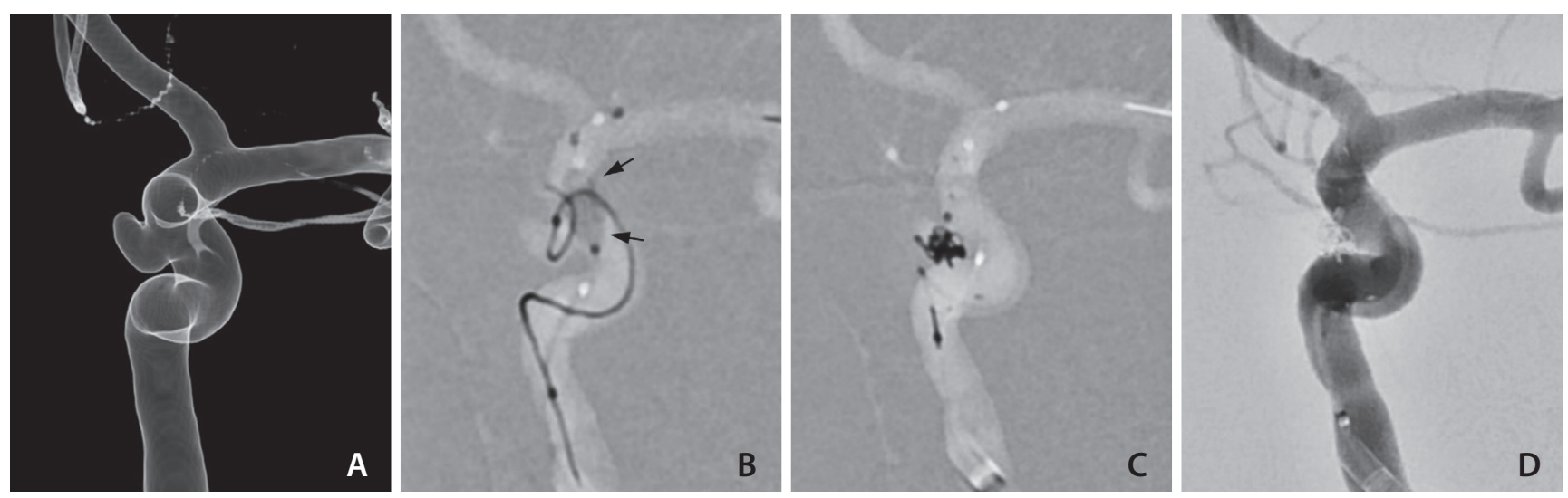

Fig. 4. Exchange into stenting after the failure of balloon-assisted coiling. (A) Left internal carotid angiogram shows an aneurysm projecting medially. (B) Despite using a balloon (arrows), the coil protrudes out of the aneurysm. (C) After deploying a stent, the coil is packed in the aneurysm. (D) Complete obliteration of the aneurysm is achieved. 
follow-up period and reported as hemorrhagic and ischemic. Patient functional outcome was assessed at discharge and the 1-and 6-month follow-up visits using the modified Rankin Scale (mRS) score.

\section{RESULTS}

\section{Aneurysm Characteristics}

A total of 58 patients with 58 unruptured paraclinoid aneurysms (average maximum diameter, $4.7 \pm 1.4 \mathrm{~mm}$ ) were enrolled (Table 1). Of these 58 aneurysms, the inferior, medial, superior, and lateral groups accounted for $41.4 \%$ (24/58), $39.7 \%$ (23/58), $10.3 \%$ (6/58), and 8.6\% (5/58) of the aneurysms, respectively. The average dome-to-neck ratio was 1.5 and $69 \%$ (40/58) of the aneurysms were considered wide-neck.

\section{Treatment Outcome}

Technical success was achieved in 51 of 58 patients (88\%). Balloon-assisted coiling was switched to stent-assisted coiling in 7 patients. The technical failure comprised of three medial group (28.6\%), two inferior group (28.6\%), and two superior group (42.9\%). The mean dome-to-neck ratio was 1.33, which was lower than the overall average. In assessing the immediate results, 35 aneurysms (60.3\%) were completely occluded, 23 (39.7\%) showed a residual neck, and none showed a residual aneurysm. The mean packing density was $37.1 \%$ (range, 26-58\%). There was no periprocedural complication.

\section{Clinical Outcome}

DWI, which was performed within 24 hours after the procedure, showed positive findings in 14 patients (24\%), but no neurologic symptoms were present. Of these, microembolism occurred in 13 patients, and acute thromboembolic infarction was observed in one (1.7\%). The acute infarction occurred in the right basal ganglia with a size of $1.3 \mathrm{~cm}$, and there was no neurological symptom or sign until the last follow-up of 7 months, but it was recorded as an ischemic event. All patients showed an mRS score of 0 at a mean follow-up duration of 17.7-months (range, 12-25 months).

\section{Imaging Follow-up}

MRA follow-up was performed in 37 patients (63.8\%) at an average of 11.8 months. Of these, complete occlusion was confirmed in 22 patients (75.8\%), and aneurysm neck filling was observed in 7 patients (24.1\%). Of the 23 patients with a residual neck initially observed, 10 showed progressive occlusion, 3 of them increased in size, and one remained unchanged. Minor recurrence occurred in 11 of 37 patients (29.7\%) who underwent follow-up, of which 8 patients newly discovered neck filling and 3 patients increased the size of

Table 1. Aneurysm characteristics and treatment outcome

\begin{tabular}{|c|c|}
\hline Variable & Value \\
\hline \multicolumn{2}{|l|}{ Aneurysm characteristics } \\
\hline \multicolumn{2}{|l|}{ Aneurysm group } \\
\hline Superior & $6(10.3)$ \\
\hline Inferior & $24(41.4)$ \\
\hline Medial & $23(39.7)$ \\
\hline Lateral & $5(8.6)$ \\
\hline \multicolumn{2}{|l|}{ Size (mm) } \\
\hline$<3$ & $1(1.7)$ \\
\hline $3-5$ & $35(60.3)$ \\
\hline $5-7$ & $15(25.9)$ \\
\hline$\geq 7$ & $7(12.1)$ \\
\hline Aneurysm size (mm) & $4.7 \pm 1.4$ \\
\hline Aneurysm volume $\left(\mathrm{mm}^{3}\right)$ & $47.2 \pm 43.9$ \\
\hline Dome-to-neck ratio & $1.5 \pm 0.3$ \\
\hline \multicolumn{2}{|l|}{ Treatment outcome } \\
\hline Packing density (\%) & $37.1 \pm 6.8$ \\
\hline \multicolumn{2}{|l|}{ Immediate results } \\
\hline Complete occlusion & $35(60.3)$ \\
\hline Residual neck & $23(39.7)$ \\
\hline Residual aneurysm & $0(0)$ \\
\hline \multicolumn{2}{|l|}{ DWI lesions } \\
\hline None & $44(75.9)$ \\
\hline Few microembolism & $10(17.2)$ \\
\hline Many microembolism & $3(5.2)$ \\
\hline Asymptomatic Infarction & $1(1.7)$ \\
\hline \multicolumn{2}{|l|}{ Adverse events } \\
\hline Ischemic & $1(1.7)$ \\
\hline Hemorrhagic & $0(0)$ \\
\hline \multicolumn{2}{|l|}{ Follow-up MRA* } \\
\hline Minor recurrence & $11(29.7)$ \\
\hline Major recurrence & $0(0)$ \\
\hline mRS score of 0 at a recent follow-up & $58(100)$ \\
\hline
\end{tabular}

Values are presented as number (\%) or mean \pm standard deviation. DWI, diffusion-weighted image; MRA, magnetic resonance angiography; mRS, modified Rankin Scale.

*Available in 37 patients. 
the existing residual neck filling. A mean of 5.3 months of radiograph follow-up was performed in 21 patients who had not yet received MRA follow-up. Of these, coil compaction was suspected in one patients on radiographs performed 7 months after the procedure.

\section{DISCUSSION}

Our study showed that the modified balloon-assisted coiling technique for the paraclinoid aneurysms initially resulted in good outcomes. We achieved a 37\% mean packing density resulting in complete occlusion and a residual neck in 60\% and $40 \%$ of the patients. This result may be comparable or better than previous reports reported $67.3-76.8 \%$ satisfactory occlusion rates (Raymond scores 1 and 2) of paraclinoid aneurysms on initial angiography. ${ }^{4}$ A switch to stent-assisted coiling was required in seven cases in our series, resulting in a 12\% (7/58) of failure rate. The stent could be deployed via the same double-lumen balloon catheter without difficulty in all seven patients. A switch to another treatment option without changing the microcatheter can be regarded as an advantage.

According to previous literatures, the risk of balloon remodeling technique was not greater than conventional techniques. ${ }^{16-18}$ Nevertheless, the safety of the technique remains a matter for debate with regards to a potential increase of thromboembolic events and intraprocedural rupture..$^{15}$ In the ATENA (analysis of treatment by endovascular approach of nonruptured aneurysms) study targeting unruptured aneurysms, the complication rates of balloon-assisted coiling were $5.4 \%$ and $3.2 \%$ for thromboembolic events and intraoperative rupture, respectively. ${ }^{17}$ Our study showed good safety results, as indicated by an overall complication rate of $1.7 \%$, even though we included only paraclinoid aneurysms. The partially inflated balloon we used does not completely occlude the parent artery; therefore, cerebral infarction due to in situ thrombus formation or perfusion reduction may be minimized. Partial ballooning that supports the microcatheter rather than fixing it also may reduce aneurysm rupture caused by a coil.

The main concept of the modified balloon-assisted coiling technique is to prevent a kick-back of the microcatheter tip from the aneurysm, which may preclude dense packing of the paraclinoid aneurysms. ${ }^{1,8}$ The counteraction between the microcatheter and the sharply angled carotid siphon often cannot be controlled by the microcatheter itself. ${ }^{31}$ Therefore, additional support of the partially inflated balloon can be added to the microcatheter curvature to stabilize the tip within the aneurysm while introducing coils. An additional advantage of the modified balloon-assisted coiling technique is the safe retrieval of the microcatheter from the packed coils within the aneurysm at the end of coil embolization as the coils are not held by the tight curve of the microcatheter tip.

The advantage of the balloon-assisted coiling over stent is that it can reduce the use of antiplatelet medication, which is particularly beneficial in patients with clopidogrel resistance. In addition, during stent-assisted coiling via a jailed microcatheter, once the microcatheter in the aneurysm sac is kickback to the parent artery, subsequent stent cell-through selection may often be difficult. The balloon is free from this difficulty. On the other hand, as in our technical failure cases, if the aneurysm neck is very wide, a stent may eventually be needed. The stent also have an advantage of reducing aneurysm recurrence by facilitating endothelialization at the aneurysm neck.

We found that the aneurysm neck in a paraclinoid aneurysm was sometimes insufficient to secure the frame coil within the aneurysm even if the neck seemed well-established and not wide relative to the aneurysm body and dome. In those situations, the introduced frame coil was not securely retained in the aneurysm and protruded out of the neck because the neck was not strong enough to keep the coil within the aneurysm. We regarded such a phenomenon as a 'pseudo-neck,' which required additional support from a balloon or stent. The modified balloon-assisted coiling technique was also helpful in protecting such pseudo-necks by controlling the position and inflation of the balloon. If the balloon-assisted coiling was unsuccessful, stenting was required.

This study has several limitations. First, the mean MRA follow-up duration was 11.8 months, and the MRA was performed in limited patients (63.8\%). Therefore, we could not assess long-term outcomes about aneurysm occlusion or recurrence rate. Further follow-up is required to confirm the long-term effects of our procedure. However, for all patients who did not undergo MRA, both immediate angiography and MRA on the next day confirmed the complete occlusion of the aneurysm. Therefore, the possibility of recurrence was considered low. Second, there may be a potential bias for the selection of the techniques among all paraclinoid aneu- 
rysms. The randomized, controlled study may be required to compare the outcomes among different techniques.

\section{CONCLUSION}

In conclusion, we describe a modified balloon-assisted coiling technique employed to successfully treat 51 (88\%) of 58 paraclinoid aneurysms. Partial inflation of the balloon to support the curved microcatheter could stabilize the microcatheter tip and improve packing density and outcome result. The technique appears to be safe and effective and could serve as an option for treating paraclinoid aneurysms.

\section{Fund}

This work was supported by the National Research Foundation of Korea (NRF) grant funded by the Korean government (MSIT) (No. 2018R1A2B6003143). The sponsor had no role in the design or conduct of this research.

\section{Ethics Statement}

The Institutional Review Board at our medical center approved this retrospective study (2020-0269) and waived the requirement to obtain written informed consent from the patients.

\section{Conflicts of Interest}

DCS received an research grant from the Microvention via the University of Ulsan, College of Medicine. All other authors certify that they have no affiliations with or involvement in any organization or entity with any financial interest (such as honoraria; educational grants; participation in speakers' bureaus; membership, employment, consultancies, stock ownership, or other equity interest; and expert testimony or patent-licensing arrangements) or non-financial interest (such as personal or professional relationships, affiliations, knowledge, or beliefs) in the subject matter or materials discussed in this manuscript.

DCS has been the Editor-in-Chief of the Neurointervention since 2018. No potential conflict of interest relevant to this article was reported.

YS has been the Assistant Editor of the Neurointervention since 2019. No potential conflict of interest relevant to this article was reported.

No other authors have any conflict of interest to disclose.

\section{Author Contributions}

Concept and design: DCS. Analysis and interpretation: YS, BK, AHA, RGK, and DCS. Data collection: YS, BK, AHA, and RGK. Writing the article: YS and DCS. Critical revision of the article: YS and DCS. Final approval of the article: YS, BK, AHA, RGK, and DCS. Statistical analysis: YS. Obtained funding: DCS. Overall responsibility: DCS.

\section{ORCID}

Yunsun Song: https://orcid.org/0000-0003-4738-0533

Boseong Kwon: https://orcid.org/0000-0002-6113-9730

Abdulrahman Hamad Al-Abdulwahhab:

https://orcid.org/0000-0003-4398-7864

Ricky Gusanto Kurniawan:

https://orcid.org/0000-0002-5738-2631

Dae Chul Suh: https://orcid.org/0000-0003-1561-5596

\section{REFERENCES}

1. Kwon BJ, Im SH, Park JC, Cho YD, Kang HS, Kim JE, et al. Shaping and navigating methods of microcatheters for endovascular treatment of paraclinoid aneurysms. Neurosurgery 2010;67:3440; discussion 40

2. Bouthillier A, van Loveren HR, Keller JT. Segments of the internal carotid artery: a new classification. Neurosurgery 1996;38:425432; discussion 432-433

3. D'Urso PI, Karadeli HH, Kallmes DF, Cloft HJ, Lanzino G. Coiling for paraclinoid aneurysms: time to make way for flow diverters? AJNR Am J Neuroradiol 2012;33:1470-1474

4. Wang $Y$, Li Y, Jiang $C$, Jiang F, Meng H, Siddiqui AH, et al. Endovascular treatment of paraclinoid aneurysms: 142 aneurysms in one centre. J Neurointerv Surg 2013;5:552-556

5. Kwon WH, Jeong HW, Kim ST, Seo JH. Angiographic and clinical result of endovascular treatment in paraclinoid aneurysms. Neurointervention 2014;9:83-88

6. Suh SH. The annual trends between neurointerventional and neurosurgical procedures in Korea: analysis using HIRA data from 2010 to 2016. Neurointervention 2017;12:77-82

7. Sun Y, Li Y, Li AM. Endovascular treatment of paraclinoid aneurysms. Interv Neuroradio/ 2011;17:425-430

8. Cho YD, Rhim JK, Park JJ, Jeon JS, Yoo RE, Kang HS, et al. Microcatheter looping to facilitate aneurysm selection in coil embolization of paraclinoid aneurysms. Korean J Radiol 2015;16:899905

9. Sheen JJ, Suh DC. Low-angled microcatheter approach for coil 
embolization of the anterior choroidal artery aneurysm. Neuroradiology 2017;59:1053-1056

10. Nelson PK, Levy DI. Balloon-assisted coil embolization of widenecked aneurysms of the internal carotid artery: medium-term angiographic and clinical follow-up in 22 patients. AJNR Am J Neuroradio/ 2001;22:19-26

11. Santillan A, Gobin YP, Mazura JC, Meausoone V, Leng LZ, Greenberg E, et al. Balloon-assisted coil embolization of intracranial aneurysms is not associated with increased periprocedural complications. J Neurointerv Surg 2013;5 Suppl 3:iii56-iii61

12. Pop R, Harsan O, Martin I, Mihoc D, Richter JS, Manisor M, et al. Balloon-assisted coiling of intracranial aneurysms using the Eclipse 2L double lumen balloon. Interv Neuroradiol 2020;26:291-299

13. Wallace AN, Samaniego E, Kayan Y, Derdeyn CP, Delgado AImandoz JE, Dandapat S, et al. Balloon-assisted coiling of cerebral aneurysms with the dual-lumen Scepter XC balloon catheter: experience at two high-volume centers. Interv Neuroradiol 2019;25:414-418

14. Spiotta AM, Miranpuri A, Hawk H, Chaudry MI, Turk AS, Turner $\mathrm{RD}$. Balloon remodeling for aneurysm coil embolization with the coaxial lumen Scepter C balloon catheter: initial experience at a high volume center. J Neurointerv Surg 2013;5:582-585

15. Sluzewski M, van Rooij WJ, Beute GN, Nijssen PC. Balloon-assisted coil embolization of intracranial aneurysms: incidence, complications, and angiography results. J Neurosurg 2006;105:396399

16. Shapiro M, Babb J, Becske T, Nelson PK. Safety and efficacy of adjunctive balloon remodeling during endovascular treatment of intracranial aneurysms: a literature review. AJNR Am J Neuroradiol 2008;29:1777-1781

17. Pierot L, Spelle L, Leclerc X, Cognard C, Bonafé A, Moret J. Endovascular treatment of unruptured intracranial aneurysms: comparison of safety of remodeling technique and standard treatment with coils. Radiology 2009;251:846-855

18. Pierot L, Cognard C, Anxionnat R, Ricolfi F; CLARITY Investigators. Remodeling technique for endovascular treatment of ruptured intracranial aneurysms had a higher rate of adequate postoperative occlusion than did conventional coil embolization with comparable safety. Radiology 2011;258:546-553

19. Jia ZY, Shi HB, Miyachi S, Hwang SM, Sheen JJ, Song YS, et al. Development of new endovascular devices for aneurysm treat- ment. J Stroke 2018;20:46-56

20. Kim JJ, Cho KC, Jung WS, Suh SH. Endovascular treatment for intracranial aneurysms: a nationwide survey in Korea. Neurointervention 2020;15:18-24

21. Shapiro M, Becske T, Riina HA, Raz E, Zumofen D, Jafar JJ, et al. Toward an endovascular internal carotid artery classification system. AJNR Am J Neuroradiol 2014;35:230-236

22. Brinjikji W, Cloft HJ, Kallmes DF. Difficult aneurysms for endovascular treatment: overwide or undertall? AJNR Am J Neuroradiol 2009;30:1513-1517

23. Lee D, Song Y, Shin JH, Suh DC. Low-dose prasugrel in patients with resistance to clopidogrel for the treatment of cerebral aneurysms: follow-up of over 6 months. Neurointervention 2019;14:68-70

24. Lee D, Song Y, Han M, Park D, Suh DC. Low-dose prasugrel in patients with resistance to clopidogrel for the treatment of cerebral aneurysms. Neurointervention 2018;13:124-127

25. Kurniawan RG, Song Y, Kwon B, Ahn Y, Suh DC. Tailored antiplatelet agent medication in clopidogrel hyporesponsive patients before stent-assisted coiling: single-center experience. Neuroradiology 2020;62:1709-1715

26. Jia ZY, Song YS, Sheen JJ, Kim JG, Lee CW, Suh DC. Loop microcatheter technique for coil embolization of paraclinoid aneurysms. Acta Neurochir (Wien) 2018;160:1755-1760

27. Kim DY, Park JC, Kim JK, Sung YS, Park ES, Kwak JH, et al. Microembolism after endovascular treatment of unruptured cerebral aneurysms: reduction of its incidence by microcatheter lumen aspiration. Neurointervention 2015;10:67-73

28. Cho YD, Kim KM, Lee WJ, Sohn CH, Kang HS, Kim JE, et al. Timeof-flight magnetic resonance angiography for follow-up of coil embolization with enterprise stent for intracranial aneurysm: usefulness of source images. Korean J Radiol 2014;15:161-168

29. Roy D, Milot G, Raymond J. Endovascular treatment of unruptured aneurysms. Stroke 2001;32:1998-2004

30. Raymond J, Guilbert F, Weill A, Georganos SA, Juravsky L, Lambert $A$, et al. Long-term angiographic recurrences after selective endovascular treatment of aneurysms with detachable coils. Stroke 2003;34:1398-1403

31. Yamaguchi S, Ito O, Koyanagi Y, Iwaki K, Matsukado K. Microcatheter shaping using intravascular placement during intracranial aneurysm coiling. Interv Neuroradio/ 2017;23:249-254 